\title{
Feasibility of Thorium Fuel Cycles in a Very High Temperature Pebble-Bed Hybrid System
}

\author{
L.P. Rodriguez ${ }^{1}$, D. Milian ${ }^{1}$, C.R. García ${ }^{1}$, D.E. Milian ${ }^{1}$, \\ C.A. Brayner ${ }^{2}$ and M. Cadavid ${ }^{3}$ \\ ${ }^{1}$ Higher Institute of Technologies and Applied Sciences (InSTEC), Avenida Salvador Allende Esq. \\ Luaces, Quinta de los Molinos, 10600 Havana, Cuba \\ ${ }^{2}$ Department of Nuclear Energy, Federal University of Pernambuco, \\ Avenida Prof. Luiz Freire, 1000 Cidade Universitária, 50740540 Recife, PE, Brazil \\ ${ }^{3}$ Tecnología Nuclear Médica Spa (TNM), Latadia, Las Condes, 4250 Santiago, Chile
}

\section{ARTICLE INFO}

\section{Article history:}

Received 09 February 2015

Received in revised form 12 May 2015

Accepted 20 May 2015

\section{Keywords:}

Very high temperature reactor

Accelerator driven system

Pebble bed reactor

Thorium fuel cycles

MCNPX

\begin{abstract}
A B S T R A C T
Nuclear energy presents key challenges to be successful as a sustainable energy source. Currently, the viability of the use thorium-based fuel cycles in an innovative nuclear energy generation system is being investigated in order to solve these key challenges. In this work, the feasibility of three thorium-based fuel cycles ${ }^{232} \mathrm{Th}^{233} \mathrm{U},{ }^{232} \mathrm{Th}-{ }^{239} \mathrm{Pu}$, and $\left.{ }^{232} \mathrm{Th}-\mathrm{U}\right)$ in a hybrid system formed by a Very High Temperature Pebble-Bed Reactor (VHTR) and two Pebble-Bed Accelerator Driven Systems (ADSs) was evaluated using parameters related to the neutronic behavior such as nuclear fuel breeding, minor actinide stockpile, the energetic contribution of each fissile isotope, and the radiotoxicity of the long lived wastes. These parameters were used to compare the fuel cycles using the well-known MCNPX ver. 2.6e computational code. The results obtained confirm that the ${ }^{232} \mathrm{Th}^{233} \mathrm{U}$ fuel cycle is the best cycle for minimizing the production of plutonium isotopes and minor actinides. Moreover, the inclusion of the second stage in the ADSs demonstrated the possibility of extending the burnup cycle duration and reducing the radiotoxicity of the discharged fuel from the VHTR.
\end{abstract}

\section{INTRODUCTION}

The world's population projections estimate an additional 1.5 billion people by 2030 and another 1 billion by 2050, bringing the world's population to about 9.3 billion. Such is Earth's predicted population growth, and it is projected that the development of the world economy will cause an increase in the electricity demand from $21300 \mathrm{TWh}$ in the year 2010 to between 30390 and $35470 \mathrm{TWh}$ by the year 2030 and between 37660 and 46190 TWh by the year 2050 [1]. However, this would bring about negative environmental impacts and potential long-term consequences. In order to face this challenge, the international scientific

\footnotetext{
* Corresponding author.

E-mail address: lorenapilar@instec.cu

DOI: http://dx.doi.org/10.17146/aij.2015.378
}

community must increase the use of energy supplies that are clean, safe, and cost-effective. Nuclear energy can be used now and in the future to meet the growing demand for energy safely and economically, with certainty of long-term supply and without adverse environmental impacts. Currently, 31 countries operate 438 reactors, with a total capacity of $375.504 \mathrm{GW}(\mathrm{e})$, and 71 further units are under construction with a total capacity of 67.027 GW(e) [2]. By the year 2035 the global nuclear capacity is projected to increase by $58 \%$. To deliver these benefits and solve some challenges linked to the nuclear energy, a new generation of innovative nuclear energy systems known as Generation IV is under research and development [3].

In this paper, the operation of a hybrid system comprised by a Very High Temperature Pebble-Bed Reactor (VHTR) and two Pebble-Bed Accelerator- 
Driven Systems (ADSs) will be studied. As a first step, the nuclear fuel will be burned in the VHTR. When the fuel charged in the VHTR is not capable of sustaining the chain reaction, it is moved to the ADSs, which are systems that combine a fission reactor, operated in a sub-critical mode, and a high power proton accelerator to control the dynamic behavior of such a system during normal operation. This is the key to the motivation for the use of these systems [4]. Both systems will use TRISO fuel and a variety of fuel cycles based on thorium $\left({ }^{232} \mathrm{Th}\right.$ ${ }^{233} \mathrm{U},{ }^{232} \mathrm{Th}-{ }^{239} \mathrm{Pu}$, and $\left.{ }^{232} \mathrm{Th}-\mathrm{U}\right)$. Parameters related to the neutronic behavior, such as nuclear fuel breeding, minor actinide stockpile, the energetic contribution of each fissile isotope, and the radiotoxicity of the long lived wastes, are used to compare the fuel cycles using the well-known MCNPX ver. 2.6e computational code.

\section{THEORY}

In this paper, the operation and main advantages of once-through and two-stage fuel cycles based on ${ }^{232} \mathrm{Th}+{ }^{233} \mathrm{U},{ }^{232} \mathrm{Th}+{ }^{239} \mathrm{Pu}$, and ${ }^{232} \mathrm{Th}+\mathrm{U}$ fuel mixtures, in the hybrid system defined and optimized in previous studies [5], reaching a deep fuel burnup, are described. In the first case, the fuel is a mixture of ${ }^{232} \mathrm{Th}(94 \%)$ and ${ }^{233} \mathrm{U}(6 \%)$, in the second case the fuel is a mixture of ${ }^{232} \mathrm{Th}(92 \%)$ and ${ }^{239} \mathrm{Pu}(8 \%)$, and in the third case the fuel is a mixture of ${ }^{232}$ Th $(40 \%)$ and $U(60 \%$, enriched to $8 \%$ $\left.{ }^{235} \mathrm{U}\right)$. The proportions for the used mixtures were selected in order to reach a discharge burnup of $75 \mathrm{GWd} /$ ton in the VHTR.

As the first step, the nuclear fuel is burned in the VHTR until the fuel is no longer capable of sustaining the chain reaction. Then, as the second step of the deep burn strategy, the nuclear fuel is moved to the ADSs. When the energy generated in the ADSs is minor compared to the energy they consume, the fuel will be sent to a geological repository. Helium gas was chosen in both systems as coolant even though it is more expensive than other gases like $\mathrm{CO}_{2}$ or nitrogen because it is transparent to neutrons, chemically inert, and does not induce graphite oxidation.

\section{Very high temperature reactor}

The Very High Temperature Reactor system (Fig. 1) is presented as one of the principal systems of the next generation of nuclear reactors (Generation IV) and is a next step in the evolutionary development of high-temperature gascooled reactors. The VHTR can generate electricity with high efficiency, over $50 \%$ at $1000^{\circ} \mathrm{C}$. Cogeneration of heat and power makes the VHTR an attractive heat source for large industrial complexes. The VHTR system is highly ranked in terms of economy because of its high hydrogen production efficiency, and in terms of safety and reliability because of the inherent safety features of the fuel and the reactor. It is rated good in proliferation resistance and physical protection, and neutral in sustainability because of its open fuel cycle. It is primarily envisioned for missions in hydrogen production and other process-heat applications, although it could produce electricity as well [3].

VHTRs are expected to have attractive features like low electricity generation costs and short construction periods. The development of this technology is based on the experience from High Temperature Gas Reactors (HTGRs) like the Dragon reactor in England, the Peach Bottom Nuclear Generating Station unit 1 in the United States, and the German Work Group Experimental Reactor (AVR) and Thorium High Temperature Reactor (THTR), both in Germany. The above mentioned reactors are experimental reactors built in the 60 s to prove their viability for electricity and heat cogeneration. They were able to reach high coolant temperatures at the core's outlet. Current projects, i.e. HTTR-2000, in Japan and HTR-10, in China, which became operational in the years 2000 and 2003, respectively, are able to reach coolant outlet temperatures of higher than $950^{\circ} \mathrm{C}$ [3].

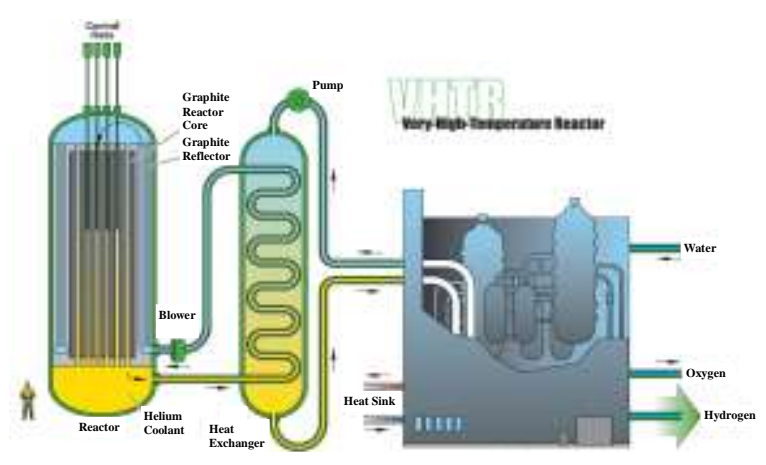

Fig. 1. Very High Temperature Reactor [3].

\section{Accelerator driven systems}

In contrast to conventional nuclear reactors in which there are enough neutrons to sustain a chain reaction, sub-critical systems used in ADS need to combine a high power proton accelerator, as an external source of neutrons, and a fission reactor operated in a sub-critical mode in order to sustain the chain reaction. More exactly, the accelerator produces high-energy protons which then interact 
with a spallation source to produce neutrons. The fission reactor uses the external neutrons, which are produced by spallation processes, in order to sustain stable power generation. The dynamic behavior of such a system during normal operation is not controlled by the reactivity coefficients of the reactor; rather, it is determined by the proton beam. The accelerator, described in [6], is a cyclotron with six separate sectors and four accelerating cavities. It is able to reach an energy of $1 \mathrm{GeV}$ with a proton beam intensity of $10 \mathrm{~mA}$. The spallation target is based on eutectic lead-bismuth in molten state with an innovative geometrical design for the separation window between the beam tube and the target.

The ADS allows one to have more control and flexibility in the design and operation of the sub-critical reactor. This is required when the reactor is being used to transmute large amounts of nuclear waste in the form of minor actinides (MA) or a fuel which, because of its poor safety characteristics, cannot be used in a critical reactor. Today it appears that ADS has great potential for waste transmutation and that such systems may go a long way in reducing the amounts of waste and thereby reducing the burden of underground repositories [4]. In an ADS, neutron cascades are used in a subcritical assembly to transmute the unwanted wastes into less harmful species. Current ADS designs suggest operating with an effective multiplication factor of up to 0.95 to ensure subcritical operation under any circumstances and limited neutron source power.

\section{Triso}

TRISO coated fuel particle (Figure 2) has been used in several reactors in the past, e.g., the $330 \mathrm{MW}(\mathrm{e})$ Fort St. Vrain reactor in the US and the $15 \mathrm{MW}(\mathrm{e})$ AVR and $300 \mathrm{MW}(\mathrm{e})$ THTR reactors in Germany. Currently, TRISO coated particle fuel is being used in the $10 \mathrm{MW}(\mathrm{t})$ HTR-10 research reactor in China and the $30 \mathrm{MW}(\mathrm{t})$ HTTR research reactor in Japan [3].

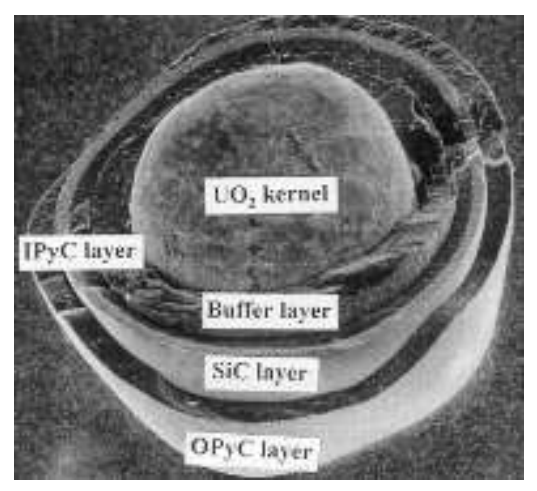

Fig. 2. TRISO coated fuel particle.
The typical fuel particle has five components. At the center, there is a fuel kernel. Immediately surrounding this kernel is a low density pyrolytic carbon buffer layer intended to provide a porous medium to absorb fission products. Enclosing this buffer layer are three near isotropic structural layers. The inner and outer layers are constructed of a high density pyrolytic carbon (PyC), the IPyC and OPyC, respectively. Between these $\mathrm{PyC}$ layers there is a layer of silicon carbide $(\mathrm{SiC})$ which serves as the pressure vessel for the particle. These particles are called tri-isotropic or TRISO particles. Thousands of these particles are combined with a matrix material and pressed into spheres for pebble bed fuels or cylindrical or annular compacts for prismatic fuels [3].

\section{Thorium as nuclear fuel}

Fuel cycles based on thorium are the options that may provide an opportunity to use the vast deposits of this nuclear material to supply future large scale deployments of nuclear energy systems and enhance the sustainability of nuclear power, since it is about three to four times as abundant as uranium. It is also a widely distributed natural resource, readily accessible in many countries. ${ }^{232} \mathrm{Th}$ is a fertile material that can be converted in nuclear reactors into fissile material which can be used for the energy generation in a similar way to naturally occurring ${ }^{235} \mathrm{U}$. Thorium utilization can play an important role in making nuclear power a sustainable energy source because it reduces the risk of nuclear proliferation and generation of long-term radioactive waste, thus increasing the safety and economy of nuclear power, making thorium advantageous as an energy resource [7].

In this paper, three thorium-based fuel cycles are presented and compared; they are:

i. ${ }^{232} \mathrm{Th}-6 \%{ }^{233} \mathrm{U}$ : In this cycle, one fissile isotope mainly sustains the criticality of the reactor. The isotope is ${ }^{233} \mathrm{U}$, which includes a certain percentage of the fresh fuel and the ${ }^{233} \mathrm{U}$ produced by the transmutation of the fertile isotope ${ }^{232} \mathrm{Th}$.

ii. ${ }^{232} \mathrm{Th}-8 \%{ }^{239} \mathrm{Pu}$ : In this cycle two fissile isotopes mainly sustain the criticality of the reactor. Those isotopes are ${ }^{239} \mathrm{Pu}$, which represents a certain percentage of the fresh fuel, and ${ }^{233} \mathrm{U}$, which is produced by transmutation of the fertile isotope ${ }^{232} \mathrm{Th}$.

iii. $40 \%{ }^{232} \mathrm{Th}-60 \% \mathrm{U}$ enriched to $8 \%$ in ${ }^{235} \mathrm{U}$ : In this cycle three fissile isotopes mainly sustain the criticality of the reactor. Those three isotopes are: ${ }^{235} \mathrm{U}$, which represents a certain percentage 
of the fresh uranium; ${ }^{233} \mathrm{U}$, which is produced by transmutation of fertile isotope ${ }^{232} \mathrm{Th}$; and ${ }^{239} \mathrm{Pu}$, which is produced by transmutation of fertile isotope ${ }^{238} \mathrm{U}$.

\section{CALCULATION METHODS}

The neutronic calculations have been performed with the MCNPX version 2.6e code [8] with the available library in XSDIR, ENDF/B VI.2. MCNPX code is based on the Monte Carlo method and incorporates the possibilities used in the present study, such as depletion/burnup capability based on CINDER90, which works with a 63-energy-group structure. CINDER90 utilizes decay and energy integrated reaction-rate probabilities along with fission yield information to calculate the temporal nuclide buildup and depletion.

It is a program for computer modeling of time dependent transportation of many types of particles, for different geometries and a wide range of energies. Monte Carlo method models probabilistic events which are included in a process, and statistically determines their probability distribution. The statistical nature of the process is based on generating random numbers to form histories. These random numbers represent each logical event that neutrons may experience and the study of the neutron trajectory from its birth until its capture or escape.

The proposed hybrid system in this paper is formed by one pebble-bed gas-cooled and graphitemoderated Very High Temperature Reactor, and two Accelerator-Driven Systems, defined and optimized in previous studies [5] and described in Table 1 and 2 . The fuel in the reactor's core is composed by TRISO coated particles confined in approximately 263465 pebbles. Both cores are surrounded by a radial graphite reflector and two axial ones, one each on the top and at the bottom.

Table 1. Main parameters of the Very High Temperature pebble-bed Reactor

\begin{tabular}{lc}
\hline Parameter & Value \\
\hline Power $(\mathrm{MWt})$ & 200 \\
Core height $(\mathrm{m})$ & 2.9394 \\
Core diameter $(\mathrm{m})$ & 4.175 \\
Core volume $\left(\mathrm{m}^{3}\right)$ & 40.24 \\
Fuel volume $\left(\mathrm{m}^{3}\right)$ & 6547 \\
No. of pebble & 263465 \\
Burnable poison & None \\
Average power density $\left(\mathrm{MW} / \mathrm{m}^{3}\right)$ & 5 \\
Packing fraction & 0.74 \\
Reflector thickness $(\mathrm{m})$ & 1.80 \\
\hline
\end{tabular}

Table 2. Main parameters of the Accelerators Device System

\begin{tabular}{lc}
\hline Parameter & Value \\
\hline Accelerator power $(\mathrm{MW})$ & 10 \\
Core internal ratio $(\mathrm{cm})$ & 15.5 \\
Core external ratio $(\mathrm{cm})$ & 148.42 \\
Height $(\mathrm{cm})$ & 293.94 \\
Total volume $\left(\mathrm{m}^{3}\right)$ & 20.12 \\
Volume of fuel $\left(\mathrm{m}^{3}\right)$ & 8.62 \\
Mass of fuel $(\mathrm{kg})$ & 1157.5 \\
No. of pebble & 131730 \\
Packing fraction & 0.74 \\
Power (MWt) & 60 \\
Average power density $\left(\mathrm{MW} / \mathrm{m}^{3}\right)$ & 3 \\
Reflector thickness $(\mathrm{m})$ & 1.80 \\
\hline
\end{tabular}

\section{RESULTS AND DISCUSSION}

The pebble's mass (10 g/pebble $)$ and the enrichment in fissile fuel $(<10 \%)$ were selected for the three fuel cycles in order to obtain a sufficient excess of reactivity to reach a discharge burnup of $75 \mathrm{GWd} /$ ton in the critical reactor (VHTR). The burnup cycle duration was 830 full power days in the reactor and 210, 400 and 1240 full power days in the ADSs for each cycle, respectively. The fuel cycle will be burnup under a deep burn scheme and a strategy of continuous recharge.

The mass variation of the fuel isotopes and Plutonium isotopes in the hybrid system as a function of time are shown in Figs. 3(a) and 3(b) for the ${ }^{232} \mathrm{Th}^{233} \mathrm{U}$ cycle, Figs. 4(a) and 4(b) for the ${ }^{232} \mathrm{Th}^{239} \mathrm{Pu}$ cycle, and Figs. 5(a) and 5(b) for ${ }^{232} \mathrm{Th}-\mathrm{U}$.

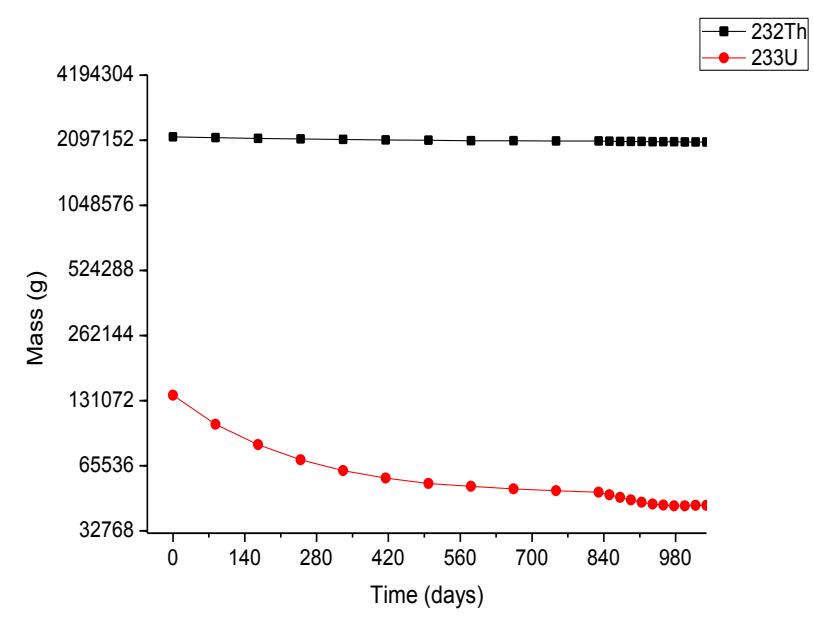

Fig. 3(a). Mass depletion of the fuel isotopes $\left({ }^{233} U\right.$ and $\left.{ }^{232} \mathrm{Th}\right)$ in ${ }^{232} \mathrm{Th}-{ }^{233} \mathrm{U}$ cycle. 


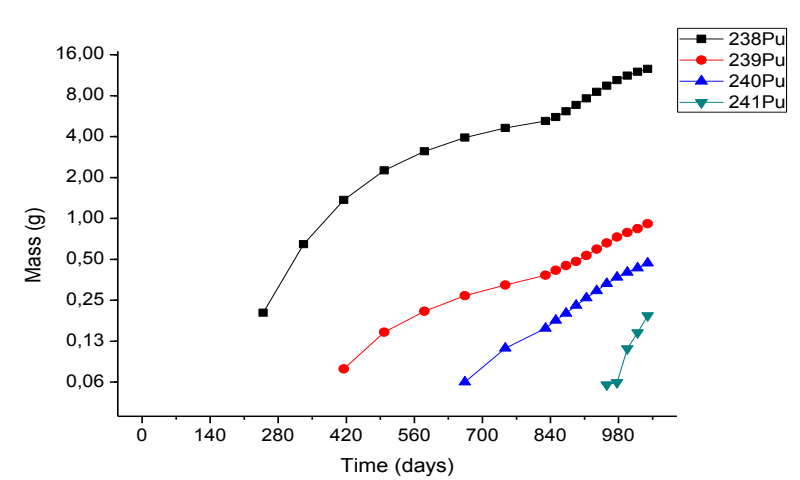

Fig. 3(b). Plutonium isotopes variation in the hybrid system ${ }^{238} \mathrm{Pu},{ }^{239} \mathrm{Pu},{ }^{240} \mathrm{Pu}$ and $\left.{ }^{241} \mathrm{Pu}\right)$ in ${ }^{232} \mathrm{Th}-{ }^{233} \mathrm{U}$ cycle.

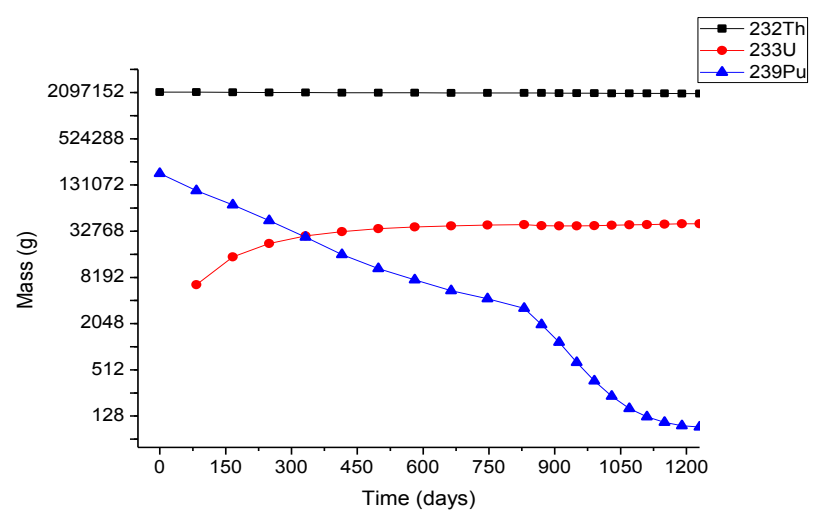

Fig. 4(a). Mass depletion of the fuel isotopes $\left({ }^{232} \mathrm{Th},{ }^{233} \mathrm{U}\right.$ and ${ }^{239} \mathrm{Pu}$ ) in ${ }^{232} \mathrm{Th}-{ }^{239} \mathrm{Pu}$ cycle.

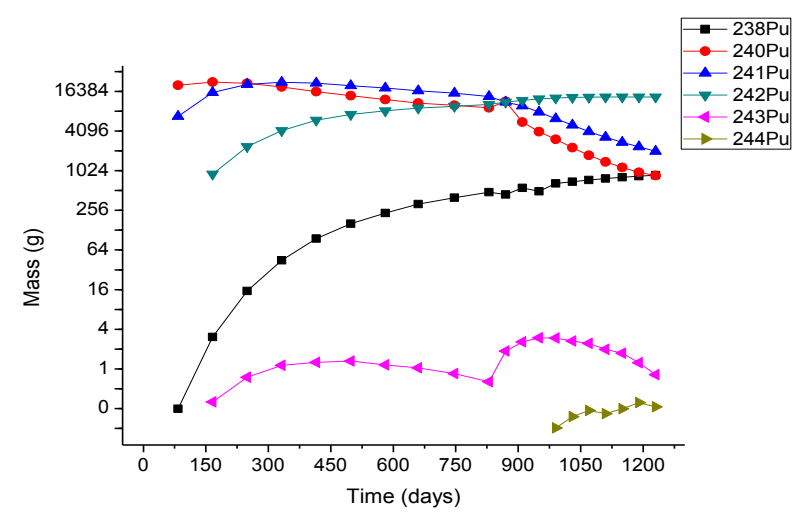

Fig. 4(b). Plutonium isotopes variation in the hybrid system ${ }^{238} \mathrm{Pu},{ }^{240} \mathrm{Pu},{ }^{241} \mathrm{Pu},{ }^{242} \mathrm{Pu},{ }^{243} \mathrm{Pu}$ and $\left.{ }^{244} \mathrm{Pu}\right)$ in ${ }^{232} \mathrm{Th}-{ }^{239} \mathrm{Pu}$ cycle.

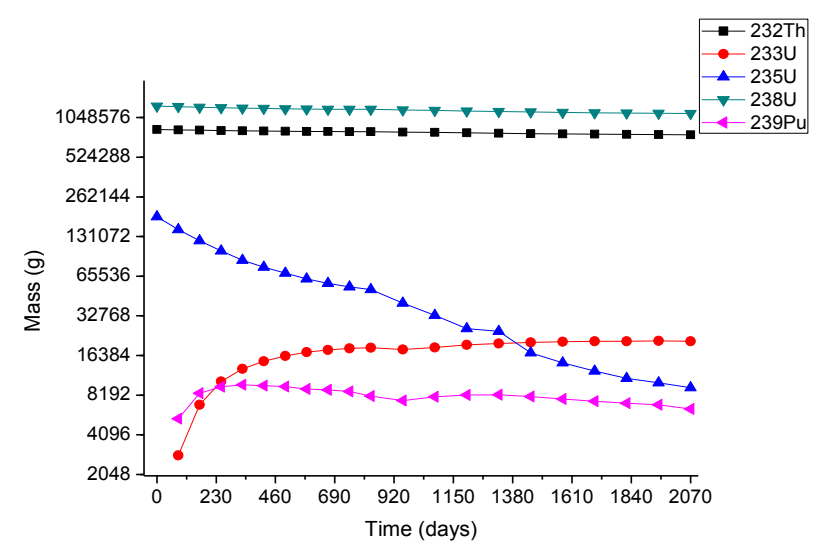

Fig. 5(a). Mass depletion of the fuel isotopes $\left({ }^{232} \mathrm{Th},{ }^{233} \mathrm{U},{ }^{235} \mathrm{U}\right.$, ${ }^{238} \mathrm{U}$ and ${ }^{239} \mathrm{Pu}$ ) in ${ }^{232} \mathrm{Th}-\mathrm{U}$ cycle.

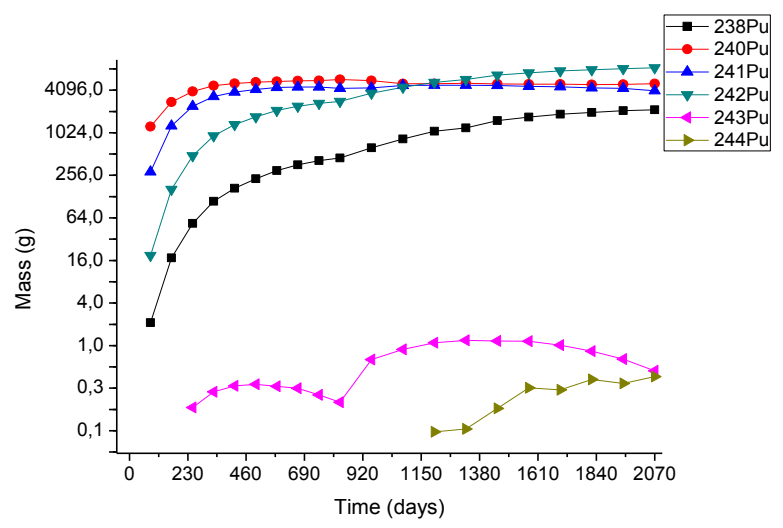

Fig. 5(b). Plutonium isotopes variation in the hybrid system $\left({ }^{238} \mathrm{Pu},{ }^{240} \mathrm{Pu},{ }^{241} \mathrm{Pu},{ }^{242} \mathrm{Pu},{ }^{243} \mathrm{Pu}\right.$ and $\left.{ }^{244} \mathrm{Pu}\right)$ in ${ }^{232} \mathrm{Th}-\mathrm{U}$ cycle.

Figure 3(a) shows a light depletion of fissile isotope ${ }^{233} \mathrm{U}$, product of the new ${ }^{233} \mathrm{U}$ obtained from transmutation of ${ }^{232} \mathrm{Th}$. It also shows how the fertile isotope ${ }^{232} \mathrm{Th}$ present minor relative variation with burnup. Figure 3(b) shows that the amount of plutonium isotopes grow in small quantities in all cases, reaching only $15 \mathrm{~g}$ at the end of the burnup cycle.

Figure 4(a) shows an important decrease of fissile isotope ${ }^{239} \mathrm{Pu}$ with respect to the loaded mass (99\% of the ${ }^{239} \mathrm{Pu}$ initially charged), and it can be seen that the mass of isotope ${ }^{233} \mathrm{U}$ presents a quasi linear growth due to the transmutation of the fertile isotope ${ }^{232} \mathrm{Th}$ and tend to reach a constant value. Figure 4(b) shows that plutonium isotopes generally present a light growth in all cases, reaching $17.3 \mathrm{~kg}$ and tend to reach a constant value.

Figure 5(a) shows that fertile isotopes ${ }^{232} \mathrm{Th}$ and ${ }^{238} \mathrm{U}$ present minor relative variation with burnup and fissile isotope ${ }^{235} \mathrm{U}$ decrease with respect to the loaded mass $\left(95 \%\right.$ of the ${ }^{235} \mathrm{U}$ initially charged) and it can be seen that the mass of ${ }^{233} \mathrm{U}$ and ${ }^{239} \mathrm{Pu}$ isotopes presents a quasi linear growth. In Figure 5(b) is shown that plutonium isotopes grow in all cases reaching $26.2 \mathrm{~kg}$ (this value include the ${ }^{239} \mathrm{Pu}$ mass).

Fuel Breeding Coefficient (BC) values (Table 3) were calculated for the fuel cycles studied using equations reported in [5,6]. In all cases, the masses of ${ }^{239} \mathrm{Pu},{ }^{239} \mathrm{U}$ and ${ }^{239} \mathrm{~Np}$ are summed because the isotopes ${ }^{239} \mathrm{U}$ and ${ }^{239} \mathrm{~Np}$ have very small $T_{1 / 2}$ and constitute intermediate isotopes between the isotopes ${ }^{238} \mathrm{U}$ and ${ }^{239} \mathrm{Pu}$. The same procedure was done with ${ }^{233} \mathrm{~Pa}$, which is also an intermediate isotope $[5,6]$. The comparison between the proposed cycles confirms that a high fuel breeding in the three fuel cycles in the hybrid system $(\mathrm{BC}=0.71,0.47$ and 0.98 respectively) can be obtained. 
Table 3. BC of the fuel cycles studied

\begin{tabular}{lcc}
\hline Fuel Cycles & Reactor BC & Reactor + ADSs BC \\
\hline${ }^{232} \mathrm{Th}+6 \%{ }^{233} \mathrm{U}$ & 0.68 & 0.71 \\
${ }^{232} \mathrm{Th}+8 \%{ }^{239} \mathrm{Pu}$ & 0.37 & 0.47 \\
${ }^{40 \%}{ }^{232} \mathrm{Th}+60 \% \mathrm{U}$ & 0.72 & 0.98 \\
\hline
\end{tabular}

A parameter that allows the evaluation of the efficiency of a one-through cycle, in which the spent fuel is destined to long term storage (fuel cycle without reprocessing), is the final percentage of fissile fuel mass (\% fissile fuel). $\%$ fissile fuel values (Table 4) were calculated for the fuel cycles studied using (1).

$$
\% \text { fissile fuel }=\frac{\text { Final mass of fissile isotopes }}{\text { Initial mass of fissile isotopes }}
$$

Table 4. \% Fissile fuel of the fuel cycles studied

\begin{tabular}{lcc}
\hline Fuel Cycles & Reactor (\%Fissile fuel) & $\begin{array}{c}\text { Reactor + ADSs } \\
\text { (\%Fissile fuel) }\end{array}$ \\
\hline${ }^{232} \mathrm{Th}+6 \%{ }^{233} \mathrm{U}$ & $38.06 \%$ & $33.78 \%$ \\
${ }^{232} \mathrm{Th}+8 \%{ }^{239} \mathrm{Pu}$ & $30.94 \%$ & $23.98 \%$ \\
${ }^{40 \%}{ }^{232} \mathrm{Th}+60 \% \mathrm{U}$ & $44.81 \%$ & $22.05 \%$ \\
\hline
\end{tabular}

In each case the final percentage of fissile fuel mass decrease due to an increase of the burnup of the fuel in the second stage in the ADSs. It was demonstrated that the inclusion of the second stage in the ADSs induced a decrease in the final percentage of fissile fuel mass (\%Fissile fuel) of $11 \%, 22 \%$ and $50 \%$ for each cycle, respectively.

The contribution of each fissile isotope to the total energy produced in the hybrid system was calculated for the fuel cycles studied. The results of the percent of release energy per isotope in each fuel cycle are indicated in Table 5 .

In each fuel cycle the major energetic contribution to the release energy is the initial fissile isotope. In the ${ }^{232} \mathrm{Th}-{ }^{233} \mathrm{U}$ fuel cycle, it is the fissile isotope; in the ${ }^{232} \mathrm{Th}^{239} \mathrm{Pu}$ cycle, it is the fissile isotope ${ }^{239} \mathrm{Pu}$; and in the ${ }^{232} \mathrm{Th}-\mathrm{U}$ cycle, a balance occurs between the initial fissile isotope ${ }^{235} \mathrm{U}$ and the produced fissile isotope ${ }^{239} \mathrm{Pu}$.

Table 5. Energetic contribution of the fuel cycles studied

\begin{tabular}{cccc}
\hline \multirow{2}{*}{ Isotopes } & \multicolumn{3}{c}{ Energetic contribution of each fissile isotope (\%) } \\
\cline { 2 - 4 } & ${ }^{232} \mathrm{Th}+6 \%{ }^{233} \mathrm{U}$ & ${ }^{232} \mathrm{Th}+8 \%{ }^{239} \mathrm{Pu}$ & $40 \% \mathrm{Th}^{232}+60 \% \mathrm{U}$ \\
\hline${ }^{233} \mathrm{U}$ & 96.00 & 19.69 & 14.42 \\
${ }^{235} \mathrm{U}$ & 3.77 & $<<1$ & 44.74 \\
${ }^{239} \mathrm{Pu}$ & $<<1$ & 80.00 & 40.82 \\
${ }^{241} \mathrm{Pu}$ & $<<1$ & $<<1$ & $<<1$ \\
\hline
\end{tabular}

The mass variations of the minor actinide isotopes in the hybrid system as function of time are shown in Fig. 6 for ${ }^{232} \mathrm{Th}^{233} \mathrm{U}$ cycle, Fig. 7 for ${ }^{232} \mathrm{Th}^{239} \mathrm{Pu}$ cycle, and Fig. 8 for ${ }^{232} \mathrm{Th}-\mathrm{U}$ cycle, respectively.

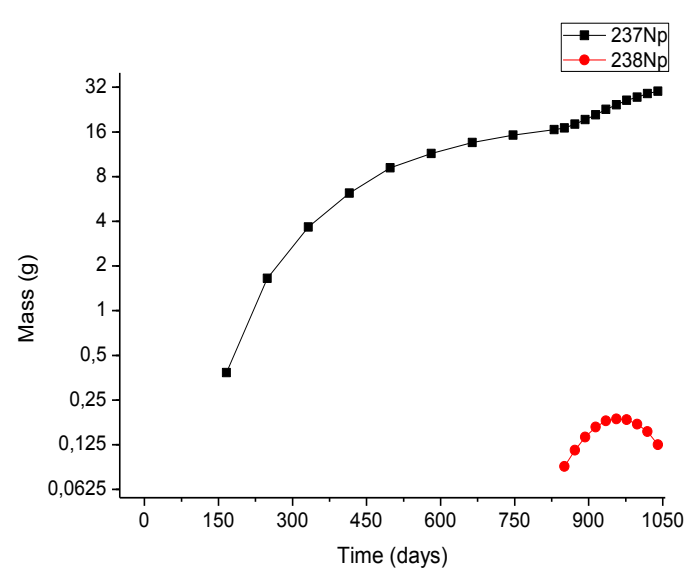

Fig. 6. Minor Actinides isotopes mass variation $\left({ }^{237} \mathrm{~Np}\right.$ and ${ }^{238} \mathrm{~Np}$ ) in the ${ }^{232} \mathrm{Th}^{2}{ }^{233} \mathrm{U}$ cycle.

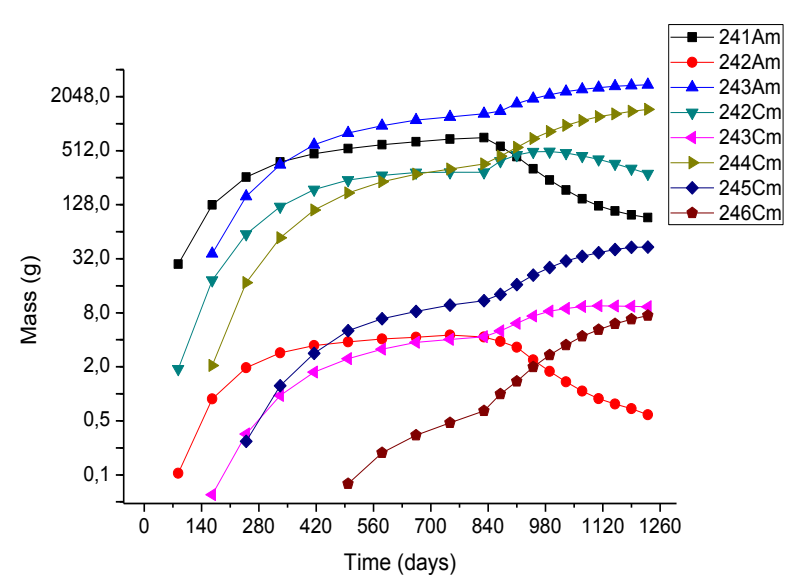

Fig. 7. Minor Actinides isotopes mass variation (Am and $\mathrm{Cm}$ ) in the ${ }^{232} \mathrm{Th}^{239} \mathrm{Pu}$ cycle.

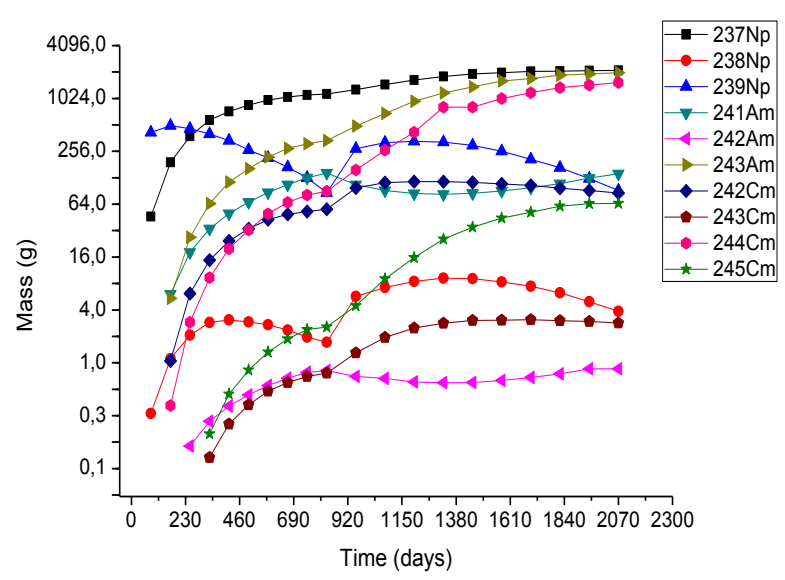

Fig. 8. Minor Actinides isotopes mass variation (Np, Am and $\mathrm{Cm}$ ) in the ${ }^{232} \mathrm{Th}-\mathrm{U}$ cycle. 
Insignificant values of masses of minor actinides are obtained for ${ }^{232} \mathrm{Th}^{233} \mathrm{U}$ cycle $(30 \mathrm{~g})$. In the ${ }^{232} \mathrm{Th}-{ }^{239} \mathrm{Pu}$ cycle and the ${ }^{232} \mathrm{Th}-\mathrm{U}$ cycle, minor actinide masses of $4.7 \mathrm{~kg}$ and $6.1 \mathrm{~kg}$, respectively, are obtained. Minor actinides masses increase in all cases except for ${ }^{239} \mathrm{~Np}$ in the ${ }^{232} \mathrm{Th}-\mathrm{U}$ cycle.

A comparison between the accumulated transuranic masses per ton of initial fuel values in the proposed cycles, and the values published for conventional LWR under a $40 \mathrm{GWd}$ /ton burn-up and a cooling time of 15 years, is illustrated in Table 6 . The ${ }^{241} \mathrm{Am}$ quantity formed from ${ }^{241} \mathrm{Pu}$ decay at the end of the whole cycle was added to the ${ }^{241} \mathrm{Am}$ quantity accumulated after a cooling time of 15 years [5,6]. For the proposed ${ }^{232} \mathrm{Th}^{-233} \mathrm{U}$ cycle only, much smaller Am and $\mathrm{Cm}$ masses are obtained, despite their being obtained for a higher burn-up (75 GWd/ton).

Table 6. Comparison of MA accumulation (Mass in $\mathrm{kg}$ per ton of initial fuel)

\begin{tabular}{lccc}
\hline \multirow{2}{*}{ Fuel Cycles } & \multicolumn{3}{c}{ Isotopes } \\
\cline { 2 - 4 } & ${ }^{241} \mathrm{Am}$ & ${ }^{243} \mathrm{Am}$ & ${ }^{244} \mathrm{Cm}$ \\
\hline${ }^{232} \mathrm{Th}+6 \%{ }^{233} \mathrm{U}$ & 0.00 & 0.00 & 0.00 \\
${ }^{232} \mathrm{Th}+8 \%{ }^{239} \mathrm{Pu}$ & 6.22 & 0.57 & 0.16 \\
$40 \%{ }^{232} \mathrm{Th}+60 \% \mathrm{U}$ & 1.94 & 0.16 & 0.04 \\
$\begin{array}{l}\text { LWR (After a cooling of } 15 \\
\text { years) }\end{array}$ & 0.77 & 0.14 & 0.03 \\
\hline
\end{tabular}

The inhalation radiotoxicity in time of the discharged fuel is shown in Fig. 9 for the VHTR and Fig. 10 for the VHTR+ADSs system.

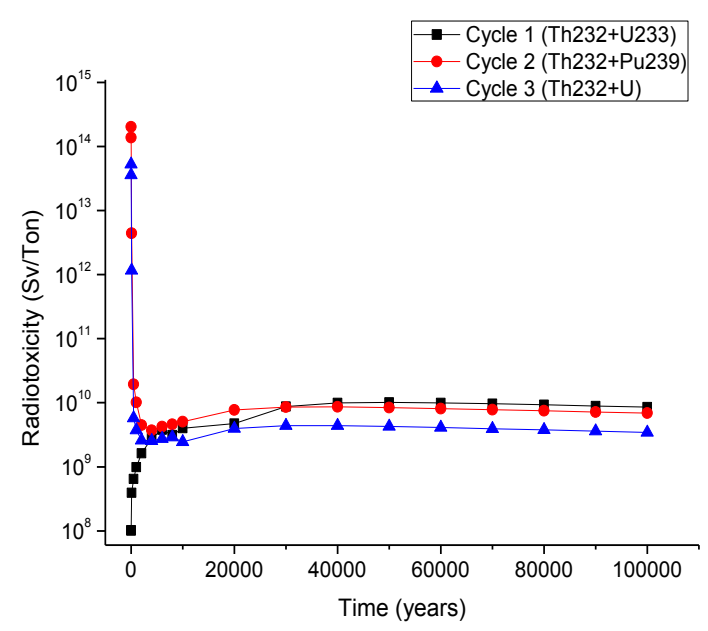

Fig. 9. Variation of the inhalation radiotoxicity, 100000 years after the fuel is discharge from the VHTR.

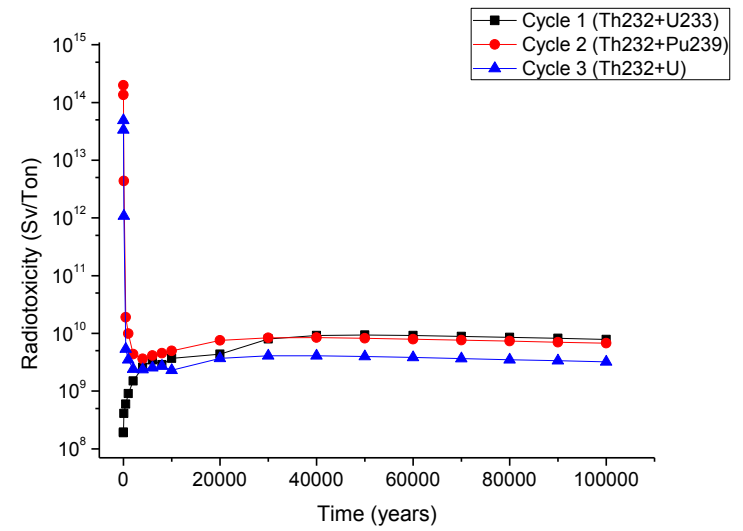

Fig. 10. Variation of the inhalation radiotoxicity, 100000 years after the fuel is discharge from the system VHTR+ADSs.

From Figure 10, it is clear that fuel cycles that contribute most to the radiotoxicity are fuel cycles 2 and 3 , initially contributing a relative radiotoxicity of $10^{14} \mathrm{~Sv} /$ ton, unlike cycle 1 , which contributes a relative radiotoxicity of the order of $10^{8} \mathrm{~Sv} / \mathrm{ton}$. In cycles 2 and 3 the radiotoxicity decreases over time, while in the cycle 1 the radiotoxicity increases. The three fuel cycles reached a radiotoxicity equilibrium concentration at 5000 years with a radiotoxicity close to $10^{10} \mathrm{~Sv} / \mathrm{ton}$. As can be seen in Fig. 13, the inclusion of the second stage in the ADSs causes an initial increase in the radiotoxicity in the cycle 1 in the order of the $49 \%$, while for the cycle 2 and 3 results in a decrease of $2 \%$ and $8 \%$. At the end of the study period (100 000 years) the inclusion of the ADSs cause a decrease in the radiotoxicity of the discharged fuel of $9 \%, 2 \%$ and $8 \%$ for the three fuel cycles, respectively, compared to the results obtained for the VHTR.

\section{CONCLUSION}

The proposed comparison in a Very High Temperature Pebble Bed Hybrid System between the proposed fuel cycles with deep burnup is achieved. In the present work, the fuel's physical parameters of the proposed fuels cycles with Thorium were optimized to achieve a final discard burnup of $75 \mathrm{GWd} /$ ton in the reactor. It was demonstrated that a relatively low enrichment in fissile isotopes $(<10 \%)$ and a mass per pebble of $10 \mathrm{~g}$ in the reactor permit the obtainment of an adequate excess of reactivity to reach an adequate cycle's duration in the critical system (830 full power days).

The inclusion of the second stage in the ADSs made extending the burnup cycle duration possible, generating a major quantity of energy with a high margin of safety. Moreover, the inclusion of 
a second stage in the ADSs induced a decrease of the discharged mass of fissile isotopes in the three fuel cycles respect to the VHTR, reducing the fissile fuel mass sent to geological repository. Additionally, the inclusion of the ADS caused an important reduction in the radiotoxicity of the discharged fuel for the three fuel cycles.

The ${ }^{232} \mathrm{Th}^{233} \mathrm{U}$ fuel cycle is demonstrated to be the best cycle for minimizing the production of plutonium isotopes and minor actinides in the Very High Temperature Pebble Bed Hybrid System. On the other hand, the ${ }^{232} \mathrm{Th}^{2}{ }^{239} \mathrm{Pu}$ fuel cycle proved its quality as an incinerator of ${ }^{239} \mathrm{Pu}$. The ${ }^{232} \mathrm{Th}-\mathrm{U}$ fuel cycle, which attained the highest breeding coefficient, showed its capacity for making a good use of the fissile fuel.

\section{REFERENCES}

1. Anonymous, International Status and Prospects for Nuclear Power 2012, Report by the Director General, IAEA (2012).

2. Anonymous, Nuclear Technology Review, IAEA (2014), http://www.iaea.org/Publications/Reports/ index.html\#ntr. Retrieved in December (2014).
3. Anonymous, Annual Report 2014 Generation IV International Forum, OECD Nuclear Energy Agency (2014).

4. Anonymous, European Roadmap for Developing Accelerator Driven Systems (ADS) for Nuclear Waste Incineration, The European Technical Working Group on ADS (2001).

5. L.P. Rodriguez, D. Milian Perez, C.G. Garcia et al., Neutronic Behavior of Thorium Fuel Cycles in a Very High Temperature Hybrid System, Proceedings of 2013 International Nuclear Atlantic Conference - INAC 2013 (2013) 148.

6. C. García, J. Rosales, L. García et al., Progress in Nuclear Energy 66 (2013) 61.

7. Anonymous, Introduction of Thorium in the Nuclear Fuel Cycle Short- to long-term considerations, OECD Nuclear Energy Agency (2015).

8. J. Hendricks, G. Gregg McKinney, J. Durkee et al., MCNPX 2.6x Extensions, LA-UR-082216, Los Alamos National Laboratory (2008) 4. 